\section{Amptek Inc.}

Tel: 781-275-2242

Email: sales@amptek.com

www.amptek.com

\section{FAST SDD ${ }^{\circledR}$ Detector for EDS (SEM)}

APPLICATIONS: Scanning Electron Microscopes $\mathrm{X}$-ray Fluorescence $\bullet$ Energy-Dispersive X-ray Spectrometry - Non-destructive Analysis - Elemental Analysis

FEATURES: SDD detectors for EDS-XRF use with SEMs by OEMs. Low energy response of the Amptek FAST SDD $®$ extends down to boron (B).

http://www.amptek.com/products/eds-sem-applications-with-c2-window/

\section{Basler, Inc.}

Tel: +1 6107170171

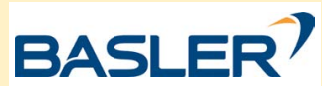

Email: sales.usa@baslerweb.com

www.baslerweb.com/microscopy

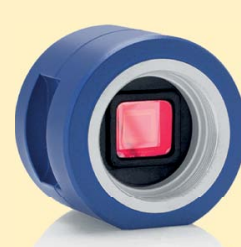

\section{Digital Microscope Cameras}

APPLICATIONS: Microscopy for Clinical \& Life Science Applications - Material Inspection \& Quality Control - Diagnostic Labs - Fluorescence Microscopy $\bullet$ Education

FEATURES: High sensitivity, excellent image quality and color reproduction, easy to use microscopy software, outstanding price/performance ratio - Basler provides over 25 years of vision technology experience and leading digital camera technology.

www.baslerweb.com/microscopy

\section{Bruker Nano Surfaces}

Tel: 805-967-1400

Email: productinfo@bruker.com www.bruker.com/AFM

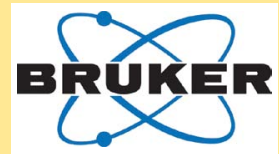

\section{Dimension FastScan AFM}

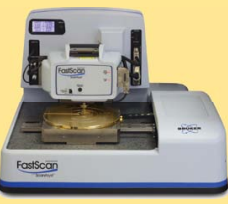

APPLICATIONS: Atomic Force Microscopes - High Resolution AFM Imaging - Nanomechanical Analysis - Nanoelectrical Measurements - Nanochemical Measurements

FEATURES: FastScan achieves the highest resolution imaging - any time, every time; unleashing bandwidth to go fast and explore real-time changes; capture complete quantitative nanoscale property data.

www.bruker.com/FastScan

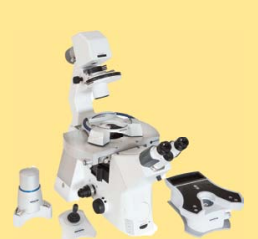

\section{BioScope Resolve AFM}

APPLICATIONS: BioAFM - Cell Mechanical Properties • Molecular Imaging • Cell Imaging

FEATURES: Resolve offers the highest resolution imaging of all biological samples while on inverted optical microscopes with comprehensive capabilities for cell mechanics and molecular force spectroscopy.

www.bruker.com/BioAFM

\section{Opterra II}

APPLICATIONS: Multipoint Confocal Microscopy - Live Cell Fluorescence Imaging - Photomanipulation - Spectral Imaging

FEATURES: Opterra II tailors speed, resolution, and intensity for low photo-toxicity and photo-bleaching on biological specimens, with sub-10\% illumination uniformity, photo-activation, spectral imaging and unmixing capabilities.

www.bruker.com/Opterra

\section{Vutara 352}

APPLICATIONS: Super-resolution Microscopy • VideoRate, Single-Molecule Localization - Quantitative Analysis Modules - Correlative High Speed Confocal Imaging

FEATURES: Vutara 352's speed, imaging depth, and resolution deliver significant advantages over competing approaches, adding real-time quantitative analyses and including pair-correlation, co-location, cluster, and live-cell analysis.

www.bruker.com/Vutara

\section{CoolLED Limited}

Tel: 1-800-877-0128

Email: info@coolled.com

www.coolled.com

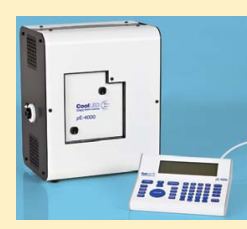

\section{CooILED pE-Series LED Illumination} Systems

APPLICATIONS: • Fluorescence Microscopy • Illuminators, Light Microscopy $\bullet$ Lamps and Light Sources - LED Illumination • Live Cell Imaging

FEATURES: CoolLED offers a comprehensive range of LED illumination systems for bioscience and clinical microscopy. Contact the CoolLED team to learn more.

http://www.coolled.com/products/

\section{Deben}

Tel: +44 (0) 1359244 870;

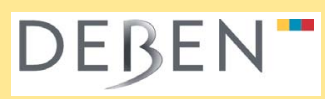

+12014105028

Email:paulg@deben.co.uk

www.deben.co.uk

\section{In-Situ Testing for Microscopy}

APPLICATIONS: Micro CT tensile scanning stages

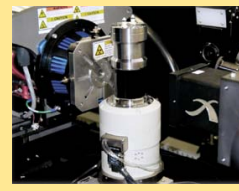

- Centaurus scintillator CL and back scattered electron (BSE) detectors - STEM detectors for SEM - SEM heating and cooling Peltier stages $•$ Microtest tensile and compression stages

FEATURES: Deben manufacture in-situ testing stages as well as innovative accessories for SEM and TEM including SEM detectors, stages, stage automation and Peltier heating \& cooling stages.

http://deben.co.uk/products/ 


\section{Companies and their Products}

\section{DiATOME U.S.}

Tel: $215-412-8390$

Email: sgkcck@aol.com

www.emsdiasum.com

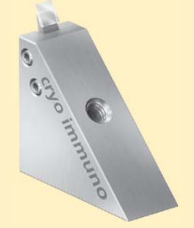

\section{Cryo Immuno}

The first cryo knife with a diamond platform and $35^{\circ}$ cutting angle that leads to a considerable reduction in mechanical stresses and therefore to improved structure preservation in sucrose-protected samples.

\section{Electro-Optics Technology, Inc.}

\section{DiATOME}

Tel: 231-935-4044

Email: sales@eotech.com

www.eotech.com

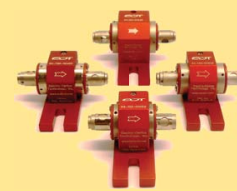

Tornos Series - 500-1030nm Wavelength Tunable Faraday Rotators and Optical Isolators

APPLICATIONS: Confocal Microscopy $\bullet$ Flow Cytometry/Optical Trapping • DNA Sequencing • Environmental Monitoring $\bullet$ Bio-instrumentation/Bio-technology

FEATURES: Eliminate frequency instability in single frequency laser diodes and prevent parasitic oscillations due to ASE in amplified laser systems. Wavelength tunability allows optimal isolation at a variety of wavelengths.

http://www.eotech.com/cart/40/free-space-optical-isolators/tornos-series500-1030nm-low-power-wavelength-tunable-optical-isolators

\section{Electron Microscopy Sciences}

Tel: 215-412-8400

E-mail: stacie@ems-secure.com

www.emsdiasum.com

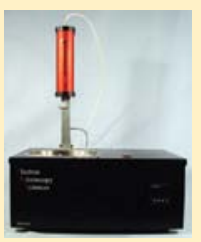

\section{EMS-002 Cryo Workstation}

The EMS-002 Cryo Workstation is a complete ultra rapid freezing system that captures rapid events and labile structures that are not seen in chemically fixed materials.

\section{Evactron by XEI Scientific}

Tel: 650-369-0133

Email: sales@evactron.com

www.evactron.com

Evactron $₫$ EP Simplified De-Contaminator APPLICATIONS: SEM and FIB remote plasma cleaner for accessory port mounting.

\section{FEATURES: Compactly mounts on chamber port. Uses air to make oxygen radicals - Simple push button control - Available tablet interface - Same cleaning power as Zephyr $\bullet$ Fast Turbo Plasma mode cleaning at $<20$ mTorr. \\ -

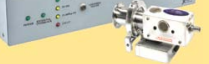

http://www.evactron.com/products/evactron-ep/

\section{ectron Sciences} Evactron ${ }^{8}$

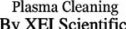

Evactron $®$ SoftClean EPтM Chamber APPLICATIONS: Desktop plasma cleaner for SEM or TEM specimens and stages - Compact EP PRS preset for optimum hydrocarbon carbon removal using air.

FEATURES: Uses removable EP plasma radical source - Push button cleaning - EasiLoader ${ }^{\mathrm{TM}}$ for TEM stages -2 TEM stage ports - Top loading for $\mathrm{SEM}$ samples • RF shielded window • Gentle cleaning without surface damage $\cdot$ Compact and simple design • Available tablet interface

http://www.evactron.com/products/evactron-softclean-chamber/

\section{Evactron $® 25 Z$ De-Contaminator}

APPLICATIONS: SEM, FIB, and vacuum chamber remote plasma cleaner for accessory port mounting - Table top controller

FEATURES: Uses air to make oxygen radicals - Preset cleaning recipes - Available computer interface - Versatile and flexible • Vacuum interlocked • Fast Zephyr mode cleaning at $<20$ mTorr

http://www.evactron.com/products/evactron-25-zephyr-de-contaminator/

Evactron $₫ 40 Z$ and $45 Z$ Decontaminator APPLICATIONS: SEM, FIB, and vacuum chamber remote plasma cleaner for accessory port mounting - Rack mount controller

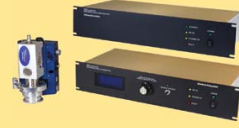

FEATURES: Uses air to make oxygen radicals $\bullet$ Preset cleaning recipes $\bullet$ Uses computer interface $\bullet$ Versatile and flexible $\bullet$ Vacuum interlocked $\bullet$ Fast Zephyr mode cleaning at $<20 \mathrm{mTorr} \bullet$ Model $40 \mathrm{Z}$ has no local controls

http://www.evactron.com/products/evactron-model-40-de-contaminator/ , http://www.evactron.com/products/evactron-model-45-de-contaminator/

\section{Evans Analytical Group}

Tel: 1-800-366-3867

Email: info@eag.com

www.eag.com $/ \mathrm{mc}$

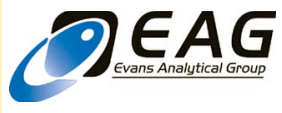

\section{Material Characterization}

APPLICATIONS: Microscopy Applications • Surface Analysis • Service Laboratories • Microanalysis Services • Failure Analysis

FEATURES: Providing high quality microscopy services including: SEM, S/TEM, CL, EBSD, FIB imaging and now: Aberration Corrected STEM services using a Hitachi HD-2700.

www.eag.com/mc

\section{EXpressLO LLC}

Tel: +1-321-663-3806

Email: info@EXpressLO.com www.EXpressLO.com

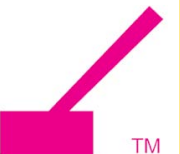

EXpressLOTM EX Situ

EXpressLO LLC

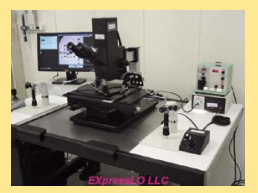
Lift Out System

APPLICATIONS: FIB Lift Out $\bullet$ Specimen Preparation - S/TEM • EBSD • Transmission Kikuchi Diffraction

FEATURES: EXpressLO ${ }^{\mathrm{TM}}$ allows fast and easy ex situ lift out - no carbon film needed. No expensive FIB time required. Simple manipulation for backside milling, EBSD, TKD.

www.EXpressLO.com 


\section{Hamamatsu Corporation hamamatsu}

Tel: 908-231-0960

Email: usa@hamamatsu.com

www.hamamatsu.com

\section{ORCA-Flash4.0}

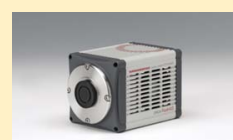

APPLICATIONS: • Super-resolution microscopy $\bullet$ Light sheet microscopy $\bullet$ TIRF microscopy $\bullet$ Ratio imaging - FRET

FEATURES: This 4.0-megapixel sCMOS camera offers enhanced quantum efficiency, $30 \mathrm{fps}$ (USB3.0) or 100 fps (Camera Link), large dynamic range, and a wide field of view.

http://www.hamamatsu.com/us/en/community/life_science_camera/product/ search/C11440-22CU/index.html

\section{Hitachi High Technologies America, Inc.}

\section{HITACHI}

Inspire the Next
Tel: 800-253-3053

Email: microscopy@hitachi-hta.com

www.hitachi-hightech.com/us

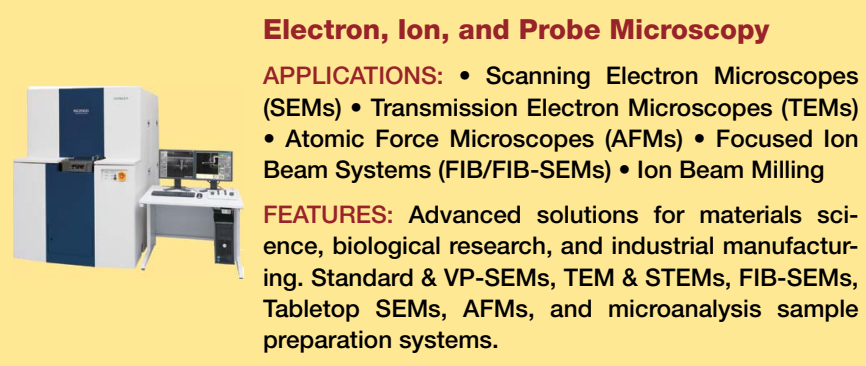

http://www.hitachi-hightech.com/us/product_list/?ld=sms2

\section{Hysitron, Inc.}

Tel: +1 952-835-6366

Email: rstromberg@hysitron.com

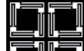

www.hysitron.com

\section{PI 8X SEM Picolndenter®}

APPLICATIONS: - Nanoindentation - Compression, Tension, Bending, and Fatigue Modes - EBSD Correlation to Mechanical Properties - Tip \& Sample Heating up to $800^{\circ} \mathrm{C} \cdot$ Nano- to micro- in-situ testing solutions

FEATURES: CoHysitron's PI 8X Series Picolndenters are compact, versatile nanomechanical test instruments for use in SEM, ESEM, FIB, and ambient conditions.

https://www.hysitron.com/products-services/instruments-for-microscopes/ pi-8x-sem-picoindenter

\section{PI 95 TEM Picolndenter®}

APPLICATIONS: • Nanoindentation and Compression - Tensile Testing of Nanowires \& Thin Films • nanoScratch $\bullet$ Fatigue $\bullet$ Electrical \& Heating Options

FEATURES: Hysitron's PI 95 TEM Picolndenter interfaces with major TEM models for performing compression, tension, bending, scratch, and fatigue testing with real-time TEM observation.

https://www.hysitron.com/products-services/instruments-for-microscopes/ pi-95-tem-picoindenter

\section{ibss Group, Inc.}

Tel: +1-650-513-1488

Email: admin@ibssgroup.com www.ibssgroup.com

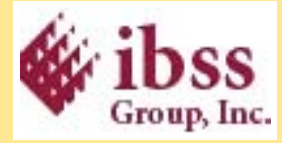

\section{GV10x Downstream Asher}

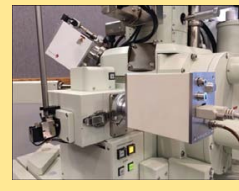

APPLICATIONS: - In-Situ Contamination Control • Ex-Situ Sample Cleaning \& Storage $\bullet$ SEM/FIB/TEM • SIMS/XPS/Review SEM • Semiconductor

FEATURES: Reduces hydrocarbon contamination $10 \mathrm{X}$ to $20 \mathrm{X}$ more effectively and $10 \mathrm{X}$ faster than traditional methods; extended power range; non-damaging; ROI short as six months.

www.ibssgroup.com

\section{International Centre for Diffraction Data}

Tel: 610-325-9814

Email: Marketing@icdd.com www.icdd.com

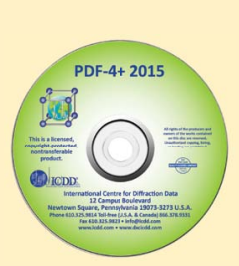

PDF-4+ 2015

APPLICATIONS: • Courses/Workshops • Databases - Journals • Materials Characterization - Phase Identification

FEATURES: PDF-4+ 2015 is a comprehensive collection of inorganic materials containing 365,877 entries, produced in a standardized format that can be rapidly searched for unknown phase identification.

http://www.icdd.com/products/2015SalesCatalog.pdf

\section{LeRoy Eyring Center for Solid State Science}

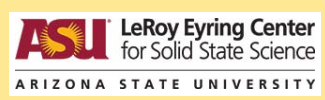

Tel: 480-727-8578

Email: jeff.luth@asu.edu

https://le-csss.asu.edu

\section{Electron Microscopy Services}

APPLICATIONS: - Microscopy Services - Materials Characterization - Surface Analysis - Instrument Training $\bullet$ Defect Analysis

FEATURES: Full range of characterization \& high resolution imaging services, including Aberration Corrected TEM/STEM/ETEM; SEM; FIB; EELS; EDS; Optical, Structural, Surface, Thermal \& Elemental analysis

https://le-csss.asu.edu/facility/john-m-cowley-center-high-resolutionelectron-microscopy 


\section{Linkam Scientific Instruments}

Tel: +44 (0) 1737363476

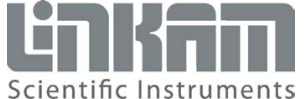

Email: Duncanstacey@linkam.co.uk

www.linkam.co.uk

\section{THMS600 Heating/Cooling stage}

APPLICATIONS: $--196^{\circ} \mathrm{C}$ to $600^{\circ} \mathrm{C}$ temperature range with liquid nitrogen - Heating rate to $150^{\circ} \mathrm{C} /$ min; cooling rate to $100^{\circ} \mathrm{C} / \mathrm{min} \cdot$ Better than $0.1^{\circ} \mathrm{C}$ accuracy and stability - Options for gas control,

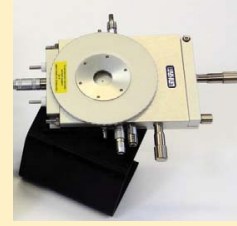

humidity, pressure, vacuum and electrical measurements - Mounts to enable vertical operation in IR or $\mathrm{X}$-ray spectrometers

FEATURES: The most versatile heating and cooling stage available. Precise temperature control. Ideal for use with light microscopy, FT-IR, UV, Raman, X-ray, SAXS and Synchrotron.

http://www.linkam.co.uk/thms600-features/

\section{CMS196M Cryo CLEM stage}

APPLICATIONS: • Self-contained cryo correlative system avoiding contamination with automated liquid nitrogen refilling $\bullet$ High precision encoded motorized $X Y$ with high speed automated mapping • Short start up time with high long-term stability and low drift - Self-aligning magnetic sample cassette system for up to three samples • Integrated condenser optics for transmitted light

FEATURES: The Linkam Cryo-CLEM stage allows vitrified samples to be imaged in brightfield and fluorescence without contamination. Grids can be mapped to provide correlative information.

http://www.linkam.co.uk/clem

\section{RH95 Humidity Generator}

APPLICATIONS: • Fully self-contained humidity control from $10 \%$ to $90 \% \mathrm{RH}$. No dry air supply required - Highly stable $+/-0.5 \%$. Ideal for long term material testing - Compatible with a range of Linkam stages and other sealed chambers up to two liters - Monitor the effects of environmental changes on a wide variety of materials - Optional calibration kit including chamber and salt ampoules

FEATURES: The RH95 Humidity Generator provides precise control of $\mathrm{RH} \%$ for a range of Linkam stages, ideal for sample characterization under changing environmental conditions.

http://www.linkam.co.uk/humidity-controller/

\section{WS37 Warm stages}

APPLICATIONS: - Calibrated, stable temperature control - ambient to $+50^{\circ} \mathrm{C} \bullet$ Ideal for andrology studies at $37^{\circ} \mathrm{C}+/-0.2^{\circ} \mathrm{C} \bullet$ Liquid crystal sensor for quick, visual, temperature calibration - Touch screen controller with control of up to two stages or objective warmer, with data logging • Ideal for live cell imaging applications

FEATURES: The WS37 warm stages have been designed for andrology applications ensuring microscope slides are held at $37^{\circ} \mathrm{C}$ for the study of sperm count and motility.

http://www.linkam.co.uk/warm-stages-features

\section{Max Levy Autograph}

Tel: 1-215-842-3675

Email: mla.custservice@ii-vi.com www.maxlevy.com

\section{Patterned Optical Components}

APPLICATIONS: - Calibration and reference standards - Resolution standards - Stage micrometers - Standards for microanalysis - Testing equipment

FEATURES: MLA offers standard and custom metrology standards for imaging. Products are available from the X-ray out to the Infrared. Traceable calibration is a capability.

http://www.maxlevy.com/category/patterned-optics.htm

\section{Meadowlark Optics}

\section{mendowlark optics}

Tel: 303-833-4333

Email: sales@meadowlark.com

www.meadowlark.com

\section{1-Photon SLM Microscopy Kit}

APPLICATIONS: Meadowlark Optics offers spatial light modulators with response times $8 \mathrm{x}$ faster than competing technologies. Our microscopy kit is ideal tool for any volumetric fluorescence studies such as calcium imaging and/or photoactivation used to monitor and manipulate up to 1500 neurons/second.

FEATURES: - Multisite scan-less excitation - Epifluorescence microscope $\bullet$ High speed hologram generator and calibration software $\bullet$ Excite and monitor activity of neuronal ensembles

http://www.meadowlark.com/spatial_light_modulators.php

\section{Microtome Service Company}

Tel: 315-451-1404

Email: Mitch@MicrotomeServiceCo.com

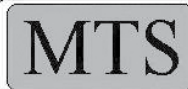

www.microtomeserviceco.com

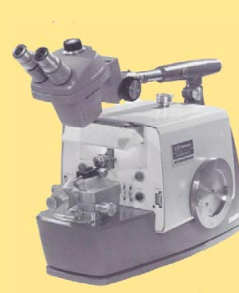

Microtome Sales, Service and Parts

APPLICATIONS: - Sorvall Microtomes and Ultramicrotomes - Rotory Microtome Repair - KnifeMaker Repairs - AO 820 \& AO 860 Repairs - Fabricate \& Modify Lab Equipment

FEATURES: Sales \& Service of Sorvall, RMC, AO:820, 860 and Rotary Microtomes and GKM Knife Makers. Microtome \& Lab accessories, fabrication and modifications to meet your specific needs. Microtome Rentals.

http://microtomeserviceco.com/index.php?route=information/ information\&information_id=7 


\section{Minitool Inc.}

Tel: (408) 395-1585

Email: rschaller@minitoolinc.com

www.minitoolinc.com

Microtools and Instruments

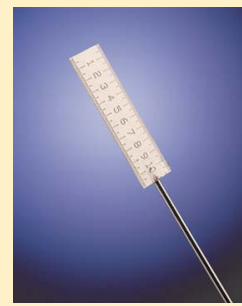

APPLICATIONS: • Microscopy $\bullet$ Microbiology $\bullet$ Specimen Manipulation \& Placement $\bullet$ Medical Research - Spectroscopy

FEATURES: Efficient, precise and realistically proportioned instruments in tip diameters from $.025 \mathrm{~mm}$ $(.001 ")$ to $1.0 \mathrm{~mm}(.040 ")$ are ideal for microscopists. Our line of micro-tools includes needles, gravers, chisels, knives, mirrors, probers, spatulas, hooks, scribes and microrulers. Also featured are micromanipulators, micro-sharpeners and micro-forceps. Tools are offered singly or in sets of eight tools with one handle to 32 tools with six handles.

www.minitoolinc.com

\section{Oregon Physics}

Tel: +1 5036010041 OREGON

Email: info@oregon-physics.com

www.oregon-physics.com

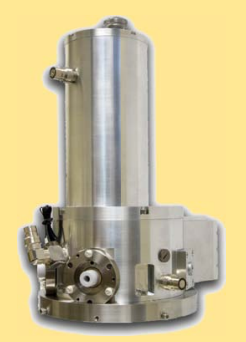

\section{Hyperion II Dual Polarity Ion Source}

APPLICATIONS: • Negative and positive ion extracton - Bolt-on to existing optical system - utilize variety of gas species - Supports surface analysis (SIMS) applications • Supports high current micromachining (PFIB) applications

FEATURES: Integrates on existing ion optical systems to deliver the highest brightness, best imaging resolution and longest source lifetime for SIMS applications or high current FIB.

http://www.oregon-physics.com/hyperion2.php

\section{FIB Consumable Parts}

APPLICATIONS: • Custom aperture strips $\bullet$ standard aperture strips • Suppressors • Extractors • For FEI FIB columns

FEATURES: Maintain optimal FIB performance. Proven, reliable parts made to exacting standards, with fast delivery assuring your parts will be in hand quickly, ready for installation.

www.oregon-physics.com

\section{PCO AG}

Tel: +1 (248) 2768820

Email: info@pco-tech.com

www.pco-tech.com

pco.flim

APPLICATIONS: • Fluorescence Lifetime Imaging Mi-

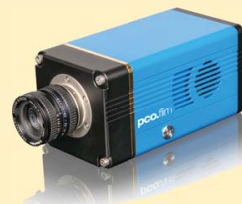
croscopy (FLIM) - Fluorescence Resonance Energy Transfer (FRET) - Confocal Microscopy - Phosphor Lifetime Imaging (PLIM)

FEATURES: The pco.flim is the first luminescence lifetime imaging camera. The camera has a revolutionary image sensor and makes use of fluorescence lifetime imaging in the frequency domain, making it suitable for numerous applications in the field of biomedical research.

http://www.pco-tech.com/special-cameras/pcoflim/

\section{Quorum Technologies \\ Ltd}

Tel: $+44(0) 1323810981$

Email: sales@quorumtech.com

www.quorumtech.com

Q150 series of SEM \& TEM sputter/carbon coaters

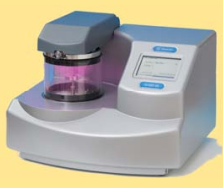

APPLICATIONS: - Scanning electron microscopy (SEM) sputter coating - TEM carbon coating - SEM carbon coating $\bullet$ Metal evaporation option $\bullet$ Thin film coating - including sequential sputter coating

FEATURES: The Q150T turbo-pumped series of coaters offer high resolution sputtering, carbon evaporation for SEM and TEM or both in one system. Three-year warranty is standard.

https://www.quorumtech.com/products/sputter-coaters-and-sem-temcarbon-coaters

\section{PP3010T Cryo-SEM/Cryo-FIB/SEM Preparation System}

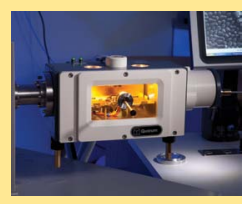

APPLICATIONS: $\bullet$ Cryo-SEM preparation and transfer - Cryo-FIB/SEM preparation and transfer • Cryo and ambient temperature transfer from glove a glove box

FEATURES: The PP3010T is a highly automated, easy to use, column-mounted, gas-cooled cryo preparation system suitable for most makes and models of SEM, FE-SEM and FIB/SEM.

https://www.quorumtech.com/quorum-product/pp3010t-cryo-sem-preparation-system

\section{Rigaku Corporation}

Tel: 281-362-2300

Email: info@rigaku.com www.rigaku.com

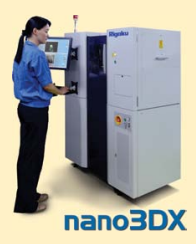

Rigaku nano3DX

APPLICATIONS: • X-ray microscope $\bullet$ computed tomography $\bullet \mathrm{XRM} \bullet \mathrm{CT} \bullet$ High Resolution

FEATURES: Nano3DX is a X-ray microscope (XRM) with the ability to measure relatively large samples at high resolution using a high powered rotating anode $X$-ray source and a CCD imager.

http://www.rigaku.com/products/xrm/nano3dx

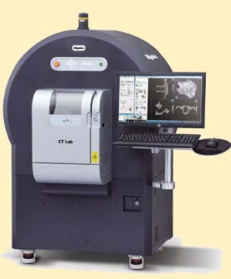

\section{Rigaku CT Lab GX series}

APPLICATIONS: - Ultra-high-speed CT scan and image reconstruction - High-resolution wide fieldof-view measurement - Uses "Sample-Stationary Method" • Low running cost

FEATURES: CT Lab GX series, for ultra-high-speed, high-resolution 3D X-ray micro CT. Using the SampleStationary Method, devices can perform CT scans in 8 seconds at top speed, with a minimum resolution of $4.5 \mu \mathrm{m}$.

http://www.rigaku.com/en/products/xrm/ctlab 


\section{SmarAct Inc}

Tel: 415-766-9006

Email: info@smaract.com

www.smaract.com

\section{SmarAct Microscopy stage}

APPLICATIONS: - Micro and nano- manipulators

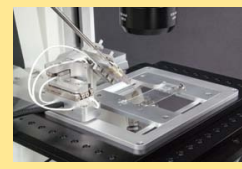

- Vacuum-compatible piezo stages - Probe testing positioners • Picoscale laser Interferometer • Microgrippers

FEATURES: SmarAct offers piezo-based high performance micro- and nanopositioners, advanced control systems; complete miniaturized manipulation systems and custom compact positioning systems that have sub-nm resolution.

http://www.smaract.de/FTP/SmarAct_Catalog_2015.pdf

\section{SPI Supplies}

Tel: 610-436-5400

Email: sales@2spi.com

www.2spi.com

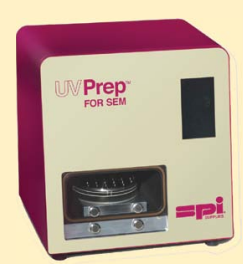

\section{UV Prep}

APPLICATIONS: • Materials Science • Life Science - Semiconductor - Low Voltage Imaging - Failure Analysis

FEATURES: The UV Prep is designed to remove hydrocarbon contamination from a sample surface prior to FE-SEM examination. The result is enhanced imaging and resolution at low accelerating voltages.

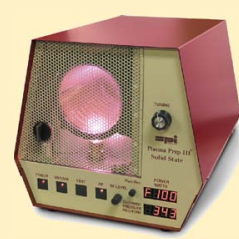

Plasma Prep ${ }^{\mathrm{TM}}$ III

APPLICATIONS: • Materials Science $\bullet$ Life Science • Semiconductor • Asbestos $\bullet$ Failure Analysis

FEATURES: Solid state RF generator capable of 1 to 100W operations; Low Temperature asher/etcher; small footprint; 4" diameter x 6" depth Pyrex or Quartz Chamber; Optional Process Controller; Optional system for cleaning TEM Specimen Holders.

\section{Wet Cell II}

APPLICATIONS: • Materials Science • Life Science • Microfluidic Analytical Techniques - Self-contained Interface $\bullet$ Vacuum Compatible

FEATURES: The next generation device for the examination of liquids in SEM/EDS and TOF-SIMS instruments. The self-contained high vacuum compatible device enables the analyst to characterize a fluid in its natural state.

\section{Sutter Instrument}

Tel: 415-883-0128

Email: alex@sutter.com

www.sutter.com

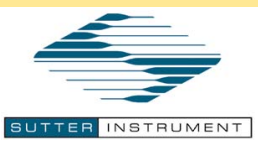

\section{SmartShutter ${ }^{\mathrm{TM}}$}

APPLICATIONS: Shuttering, Fluorescence Microscopy, Life Sciences, Imaging Hardware

FEATURES: • Life tested to 100 million cycles $\bullet$ Complete opening time $8 \mathrm{msec}$ from trigger - Select partial opening function for neutral density capability - "Soft" mode provides minimum vibration - Stand alone, or use with Sutter filter wheel

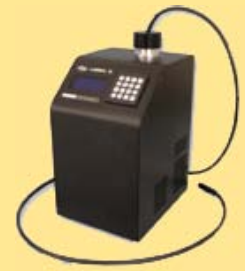

\section{Lambda XL}

APPLICATIONS: Microscope Illumination, Fluorescence Microscopy, Life Sciences, Imaging Hardware, OEM Illumination

FEATURES: • 10,000 hour expected lifetime for bulb - No high-voltage pulse $\bullet$ Highly stable output (less than $\pm \mathbf{1} \%$ fluctuations) $\bullet$ Built-in driver for Sutter filterwheel and SmartShutter $\bullet$ Low light loss through bulb life

\section{Lambda DG-4 / DG-5 PLUS}

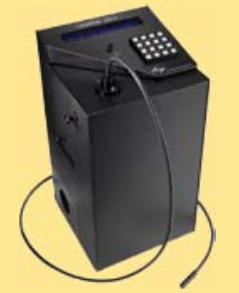

APPLICATIONS: Fluorescence Microscopy, Ratiometric Imaging, Wavelength Switching, Imaging Hardware, Life Sciences

FEATURES: - 0.5 msec switching between filters - Integrated light source and wavelength switching excitation system $\bullet$ Holds four or five interference filters and one neutral density filter $\bullet$ Light guide output provides uniform illumination - Direct computer control via parallel or serial interface

\section{Lambda 10-3}

APPLICATIONS: Fluorescence Microscopy, Ratiometric Imaging, Wavelength Switching, Imaging Hardware, Life Sciences

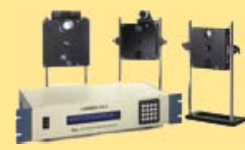

FEATURES: - As fast as $40 \mathrm{msec}$ between adjacent filters (10 position wheel) - As fast as $31 \mathrm{msec}$ between adjacent filters ( 4 position wheel) $\bullet$ Can control up to 3 wheels and 2 shutters, or 2 wheels and 3 shutters $\bullet$ Compatible with SmartShutter ${ }^{\mathrm{TM}}$ stepper-motor controlled shutter - Controls a variety of $12,25,32$, and $50 \mathrm{~mm}$ filterwheels

\section{MPC-385 / MPC-325}

APPLICATIONS: Life Sciences, Micromanipulation, Electrophysiology

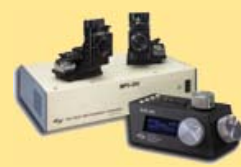

FEATURES: - Single controller and ROE will run 2 stepper motor drive manipulators - User-friendly interface: single button access to all major functions - Accelerated mode for fast, manual manipulator movement - Definable 4th axis for coaxial pipette movement - Ultra-low drift, ultra-smooth movement.

\section{SOM-Simple Moving Microscope}

APPLICATIONS: • Fluorescence Microscopy • In vivo microscopy • In vitro microscope • Life sciences - Photostimulation

FEATURES: The SOM is a small, simple microscope designed to allow a single experimental setup to be used for both in vivo and in vitro experimentation. 
Ted Pella, Inc.

Tel: 800-237-3526

Email: sales@tedpella.com

www.tedpella.com

High Resolution FE-SEM Sputter and Carbon Coaters

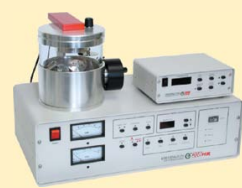

APPLICATIONS: • Life Sciences • Materials Science - Semiconductors • SEM

FEATURES: - Grain-free, ultra-thin uniform and conformal coating $\bullet$ Wide choice of operating parameters to accommodate all sample types - Purpose designed with optimized vacuum pumping system - RotaryPlanetary-Tilting stage and high resolution thickness controller $\bullet$ Easy to operate with fast cycle times

www.tedpella.com/cressington.htm

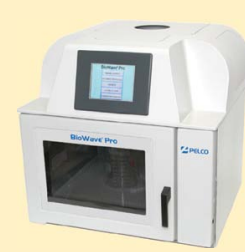

\section{PELCO BioWave® Pro}

APPLICATIONS: - Microwave Tissue Processing for EM • Light Microscopy • Immunolabeling and Decalcification

FEATURES: ColdSpot ${ }^{\circledR}$ technology - Prevents heat damage $\bullet$ Rapid specimen turnaround $\bullet$ Variable power processing $\bullet$ Pre-programmed protocols

www.tedpella.com/BioWave.htm

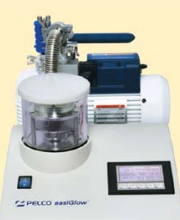

\section{PELCO easiGlow ${ }^{\text {TM }}$}

APPLICATIONS: • Life Sciences • Materials Science • TEM • Tomography

FEATURES: Precise and easy vacuum settings - Short cycle times - Consistent results - Intuitive touch screen for control and display $\bullet$ Supports hydrophilic/hydrophobic and negative/positive modes

www.tedpella.com/easiGlow.htm

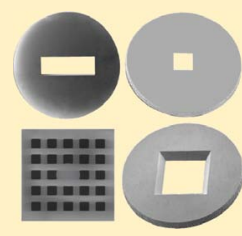

PELCO® Silicon Nitride Support Films and TEM Supplies

APPLICATIONS: • TEM • STEM • Thin Film Research - Life Sciences - Materials Science

FEATURES: Holey SiN films down to $100 \mathrm{~nm}$ - Solid membrane thickness of $8,15,35,50$ and $200 \mathrm{~nm} \cdot 3 \mathrm{~mm}$ diameter frame fits standardTEM holders $\bullet$ Easy Grip ${ }^{\text {TM }}$ edges for improved handling - Variety of window shapes and sizes

www.tedpella.com/TEM-supplies.htm

PELCO® Modular SEM/FIB Sample Holders and Supplies

APPLICATIONS: • SEM • FE-SEM • FIB • FIB/SEM - CLEM

FEATURES: Stage adapters for all major SEM brands - Large selection of effective and practical sample holders - Correlative microscopy sample holders - Conductive adhesives - Carbon tabs • Conductive tape

www.tedpella.com/SEM-supplies.htm

\section{Zemax, LLC}

Tel: 425-305-2800

Email: sales@zemax.com

www.zemax.com

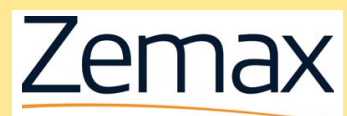

\section{OpticStudio}

APPLICATIONS: • Imaging Optics • Lighting \& Illumination $\bullet$ Lasers $\bullet$ Fibers $\bullet$ Biomedical Imaging

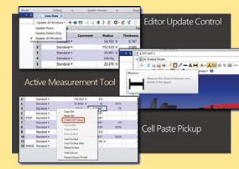

FEATURES: OpticStudio 15.5 adds speed, capability, convenience, and flexibility to the most widely used optical and illumination design software in the industry - Optimize classic lens designs $18 x$ faster, easier, and with better results $\bullet$ Added mobility for multi-user network systems with software licensing • Incorporate high-resolution holograms and phase masks into optical system designs • Deeper, easier visualization of 2D/3D optical system designs

\section{Expand your Knowledge of Microscopy with}

MSA Membership!

\section{Whether your primary focus is in the biological or the physical sciences, MSA takes your knowledge to the next level!}

Members Receive:

- A personal subscription to MSA's official journal, Microscopy and Microanalysis, and MSA's popular bi-monthly magazine, Microscopy Today.

- Peer Networking through the Society's Focused Interest Groups and Local Affiliated Societies.

- MSA Awards Programs, Scholarships, Speaker Opportunities, and much more!

\section{Join MSA Today!}

For more information:

visit www.microscopy.org

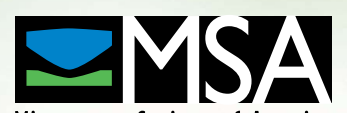

or call 1-800-538-3672 


\section{creating the best environment for microscopy...}

\section{high performance anti-vibration plattorms and workstations}

Our state-of-the art workstations and platforms are the result of many years of development. They provide the user with a truly vibration-free surface on which to place equipment. Our products are available in a wide range of sizes and shapes to support instruments of varying weights and footprints.

$2 \mathrm{~Hz}$ natural frequency built-in air isolators

Active self leveling and passive pump up versions

Highly rigid laminated construction with damping core
Low cost, easy to install and free from maintenance

- Ideal for laboratories and clean rooms, will meet Class 10 (Class 1 available)

- Simple, compact, easy to use and clean

\section{a wide range of styles, sizes, options and accessories...}

\section{Active Platforms: AMF Series}

Self-leveling and ideal for use when loads on the platform are likely to change.

\section{Passive Platforms: AMP Series}

Designed to be pumped-up and left alone. Ideal for use with fixed loads or in applications where pressurized air or gas cannot be used.

\section{Side Tables: AMT Series}

In a wide range of sizes and finishes..

Isolation Platforms: AMS Series

For heavy instruments.

\section{Balance Tables: AMB Series}

Weighted to $25 \mathrm{~kg}$ and are for use with light instruments such as balances.

High Load Workstations: AMH Series Designed for heavy instruments such as electron microscopes, which require high degrees of isolation from vibrations.

\section{Contoured Platforms: AMC Series}

Light and compact passive platform specially designed for instruments such as microscopes.

\section{please contact us for more information}

\section{Electron}

Meroscopy sciences
P.O. Box 550 - 1560 Industry Rd. • Hatfield, Pa 19440 Tel: (215) 412-8400 - Fax: (215) 412-8450 email: sgkcck@aol.com or stacie@ems-secure.com wuw.emsdiasum.com a better working environment

Workstations provide a tailored working environment as well as featuring an isolation platform built into the work surface, making working with a microscope both faster and easier, leading to more reliable measurements in your laboratory. Platforms can also be used stand alone beneath microscopes to isolate them from external disturbances and speed up measurement.

\section{flexible solutions}

We offer a range of workstations and platforms to suit different environments and microscope performance levels. Workstations feature a platform mounted on a study steel frame with height adjustable leveling feet and guards to protect the table from accidental knocks during use.

\section{ergonomic design}

The ergonomic workstation design minimizes user stress. With the active area option microscope platforms sit flush with the work surface and the surrounding area is useable for general work. Frames have height adjustable leveling feet, for stability and user comfort with retractable castor feet, frame shelf and monitor support optional.
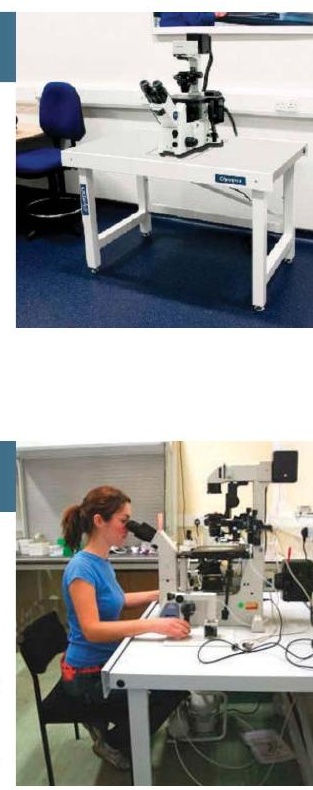